\title{
Erratum to: LeFRK2 is required for phloem and xylem differentiation and the transport of both sugar and water
}

Hila Damari-Weissler ${ }^{1} \cdot$ Shimon Rachmilevitch $^{2} \cdot$ Roni Aloni $^{3} \cdot$ Marcelo A. German $^{1}$ Shabtai Cohen ${ }^{4} \cdot$ Maciej A. Zwieniecki ${ }^{5}$ N. Michele Holbrook ${ }^{6} \cdot$ David Granot $^{1}$

Published online: 3 May 2016

(C) Springer-Verlag Berlin Heidelberg 2016

\section{Erratum to: Planta (2009) 230:795-805}

DOI 10.1007/s00425-009-0985-4

In the original article, one of the co-author's (Shimon Rachmilevitch) last name has been published incorrectly. The correct last name should be Rachmilevitch.

The online version of the original article can be found under doi:10.1007/s00425-009-0985-4.

\section{David Granot}

granot@agri.gov.il

1 Institute of Plant Sciences, Agricultural Research Organization, The Volcani Center, Bet Dagan 50250, Israel

2 Albert Katz Department of Dryland Biotechnologies, Blaustein Institute for Desert Research, Ben Gurion University, Sede Boqer Campus, Midreshet Ben-Gurion 84990, Israel

3 Department of Plant Sciences, Tel Aviv University, Tel Aviv 69978, Israel

4 Institute of Soils, Water and Environmental Sciences, Agricultural Research Organization, The Volcani Center, Bet Dagan 50250, Israel

5 Arnold Arboretum, Harvard University, 16 Divinity Ave., Cambridge, MA 02138, USA

6 Organismic and Evolutionary Biology, Harvard University, 16 Divinity Ave., Cambridge, MA 02138, USA 